\title{
Profanación y escándalo. Entendiendo la posición del arzobispado limeño en la danza de Norka Rouskaya, un siglo después
}

\author{
Fernando Armas Asin \\ Universidad del Pacífico
}

Esta nota busca explicar, en el contexto del escándalo que se produjo por el baile de Norka Rouskaya en el Cementerio General de Lima, en 1917, cuál fue la posición del arzobispado limeño. Frente a las aseveraciones que su posición fue marcadamente distinta a las que mostraron ciertos sectores católicos limeños, la nota argumenta que no fue así, buscando entenderla desde una dimensión pastoral y de los acontecimientos previos ocurridos.

\section{I}

Los hechos son harto conocidos: José Carlos Mariátegui, César Falcón y otros jóvenes periodistas, enfrentados a la sociedad aristocrática de su tiempo, desde hacía buen tiempo tenían en mente organizar una escenificación artística en el Cementerio General de Lima. En 1916, a raíz de la presentación de la Marcha Fúnebre de Chopin, por parte de la española Valencia Tórtola, se lo propusieron, pero ella se excusó. Existiendo el precedente de una presentación parecida, de Isadora Duncan en París, se lo volvieron a proponer a la bailarina suizo-italiana Norka Rouskaya, cuando en 1917 llegó a Lima. Ella aceptó entusiasmada. ${ }^{1}$

Así, y previa obtención del permiso por parte de Maríátegui ante las autoridades de la Beneficencia Pública -del cual dependía el cementerio-, poco antes de la una de la madrugada del lunes 5 de noviembre ingresaron al recinto Falcón, Mariátegui, Rouskaya, su madre, el violinista del teatro Colón, Luis Cáceres, y cuatro invitados más. Los dirigía el administrador del camposanto,

\footnotetext{
1 El asunto lo relata con detalle y cierto entusiasmo W. SteIn, Mariátegui y Norka Rouskaya. Lima: Biblioteca Amauta, 1989, pp. 48-92. Ver ahora J.C. MARIÁtegui (con el apoyo de Ana Torres y Ricardo Portocarrero), "El baile de Norka Rouskaya", El Dominical de El Comercio. Lima, 5-XI-2017, edición digital disponible en: https://elcomercio.pe/eldominical/bailenorka-rouskaya-noticia-471240.
} 
Juan Valega (La Unión, miércoles 7-XI-1917, p. 20). En unas graderías, ante la tumba de Ramón Castilla, se pusieron unas velas, siendo ayudados por los guardianes del cementerio, y mientras el violinista tocaba la Marcha Fúnebre, Norka -habiéndose sacado su abrigo- con apenas una túnica se inclina de rodillas y empieza su danza, con mucha concentración. Pero la escena dura apenas un poco más de un minuto, pues Valega desconcertado con lo que se proponía, interrumpe y se da por concluido el acto. Se retiran todos. Pero luego llega el Prefecto, notificado del hecho, los busca y aunque no los apresa cuando los encuentra en la puerta del hotel Maury, al día siguiente, presionado por el ministro de Gobierno -según se colige de las investigaciones posteriores del diario El Tiempo- da órdenes para el arresto del grupo. Las autoridades de la Beneficencia de Lima retiraron el permiso post hoc, aduciendo haber sido sorprendidos, lo que permitió el inicio de la acción policial, bajo el delito de profanación. Norka y su madre son recluidas en el convento de Santo Tomás, que fungía de cárcel de mujeres; y los hombres, incluidos el violinista y el guardián Juan Vargas Quintanilla, en la cárcel de Guadalupe (El Tiempo, martes 6-XI-1917, pp. 1-2; La Unión, miércoles 7-XI-1917, p. 20).

El rumor, en las primeras horas de la mañana, se expande por Lima: se habla de profanación de las tumbas de los muertos. Todos los investigadores coinciden que esto se hubiera amenguado si es que los periódicos no se hubieran hecho eco del incidente, con un sello sensacionalista, obligando a las autoridades a una actuación inusitada. En efecto, volviendo a leer los diarios de Lima de la época uno puede darse cuenta del sesgo con que presentaron los hechos y la evolución de sus enfoques con el paso de los días. Fue El Comercio, en su edición de la mañana del lunes 5 -a horas del incidente- quien habló primero de temeridad y falta de respeto. Y luego en la edición de la tarde, Luis Varela y Orbegozo, que firmaba sus artículos como Clovis, escribe un artículo sensacionalista, relievando la importancia de la profanación cometida. La Prensa, por su lado, esa tarde, también realza la noticia, pero subrayando el carácter excéntrico del grupo de jóvenes, e incluye la versión del joven Mariátegui, que enfatiza no fue una profanación, pues no hubo esa intención. Fue un acto artístico (El Comercio, 5-XI-1917, edición de la mañana, p. 4; edición de la tarde, p. 1; La Prensa, 5-XI-1917, edición de la tarde, p. 2).

Esa tarde del lunes el Senado de la República estuvo ganado por lo sucedido en el cementerio. Alejandro Vivanco, Manuel Pérez y el legislador eclesiástico Sánchez Díaz condenan el hecho y se pide que los ministros de Gobierno y Justicia cursen informes sobre lo ocurrido y las medidas tomadas. Mientras los senadores Secada, Ruiz Bravo y Químper señalan la nimiedad del tema, cometido por un grupo de jóvenes estrafalarios y reducido a un espectáculo que en otros lugares se hace. El día miércoles 7 todavía Mariano $\mathrm{H}$. Cornejo intervino en sonado discurso, luego reproducido en varios diarios limeños, llamando a la cordura, denunciando las faltas a la legislación sobre prisiones preventivas que han cometido las autoridades, llamando 
profanación a un acto que en mejor de los casos era una falta (El Tiempo, jueves 8-XI-1917, p. 2). ${ }^{2}$

En esa tónica, el martes 6, cuando se sopesó la magnitud de lo acontecido -estando detenidos los autores- ciertos diarios entraron al debate, planteando un enfoque distinto. El diario La Crónica, se preguntó si era arte o profanación, censurando el esnobismo de los jóvenes, pero también considerando que era "verdaderamente ridículo todo el escándalo que se ha formado", y censurando al diario El Comercio, la policía y el parlamento por centrarse en estos asuntos, siendo "lo más divertido" que los más indignados son los especializados en escándalos amorosos en una Lima de los chismes. Debió aplicarse la ley por esta profanación, que era una multa, y no más, a su criterio (La Crónica, Martes 6-XI1917, p. 4). ${ }^{3}$ Por su lado El Tiempo, diario donde trabajaban Falcón y Mariátegui, defendió desde el martes 6 la idea de que se trató de un acto artístico, diferente a la irreverencia, y que este tipo de actos se practicaban en los cementerios de París y Madrid, sin ninguna protesta (El Tiempo, martes 6-XI-1917). Además, subrayó que las autoridades accedieron en dar permiso para ingresar al recinto en madrugada, sin luz, por lo cual era dudoso que no supieran de qué se trataba. En cambio, El Comercio y La Prensa se sumergieron el martes, miércoles y hasta el jueves 8, en un mar de opiniones de diversas personas, particularmente de las autoridades de la Beneficencia Pública de Lima, como Pedro García Irigoyen (inspector del Cementerio) y Juan Valega (administrador del mismo), que buscaron rehuir sus responsabilidades.

Hoy día parece estar meridianamente claro que se trató de un escándalo pasajero, pero extrapolado a un nivel de opinión pública, por el rol de la prensa sensacionalista, en un proceso que como suele a veces ocurrir, al pasar las horas o días y existen más elementos de juicio, el tema pierde interés y se busca olvidar lo sucedido. De hecho, Mariátegui tras ser liberado el martes, en una entrevista publicada al día siguiente dejó en claro que él advirtió a las autoridades lo que Norka Rouskaya iba a ejecutar (La Prensa, miércoles 7-IX-1917, edición de la mañana, p. 3).

En el largo plazo se pudo tejer con exactitud la sucesión de hechos ocurridos: a la una de la madrugada del lunes 5 llegaron al cementerio los gendarmes de la comisaria de Ate, atraídos por la música, y dieron parte al Prefecto, Edgardo Arenas, pero éste llegó con un grupo de caballeros del Club Nacional, más para presenciar el hecho que otra cosa. Luego se dirigió al hotel Maury para arrestarlos, pero la bailarina y el grupo le explicaron lo sucedido y quedaron en

\footnotetext{
${ }^{2}$ Ver Armando BAZÁn, Mariátegui y su tiempo. Lima: Biblioteca Amauta, 1969, p. 38 y W. STEIN, Mariátegui..., pp. 93-102.

3 Según el Código Penal de 1863 de aquélla época, en su Libro Segundo, Sección Primera, artículo 107, se castigaba la profanación de templos o cementerios con pena privativa de la libertad en primer grado o segundo grado, o con multa, de acuerdo a la gravedad cometida (Código Penal del Perú. Lima, Imprenta de la Rifa, 1863, p. 36).
} 
apersonarse en la mañana a la prefectura, prometiéndoles el prefecto nada iba a ocurrir. Pero en esa mañana del lunes se detuvo a la bailarina y su madre, y luego al resto, tras la llamada del ministro de gobierno, Germán Arenas, pues el primer artículo de El Comercio volvió el hecho en algo público y Lima era un reguero de comentarios. Según los entendidos, trasgrediendo la legislación sobre prisiones preventivas, al arresto siguió la apertura de instructiva a cargo del juez del crimen Oscar Calderón. Pero el dueño del diario El Tiempo, Pedro Ruiz Bravo, pagó las fianzas, el abogado liberal Manuel Químper defendió a Rouskaya, y la vista del agente fiscal y el fallo del juez permitieron la libertad de todos los detenidos. El punto clave fue entender que no hubo profanación sino acto irrespetuoso, tal vez artístico (La Prensa, Lunes 5-XI-1917, edición de la tarde, p. 2; El Tiempo, martes 6-XI-1917, p. 2 y miércoles 7-XI-1917, pp. 1-2). Decía Abelardo Gamarra, había mujeres que iban al cementerio a extraer tierras y lo vendían a precios exorbitantes para arrojar estas "tierras de muerto" a personas a quienes se quisiera hacer daño y nadie decía nada. Sacar polvo de los cadáveres y venderlo no era peor que bailar en él, argumentaba (Integridad, 10-XI-1917, p. 1).

Desde el martes la posición de los diarios La Crónica, El Tiempo y poco después La Prensa, insistían en la naturaleza extravagante del hecho. Particularmente El Tiempo aseveraba que no existía ni actitud irrespetuosa ni menos profanación, pues La marcha fúnebre de Chopin se ejecutaba como música en los ritos mortuorios, incluso en las iglesias, y el baile de Norka Rouskaya se ejecutaba en los teatros y era considerado arte, de modo que practicarse ambas cosas en el cementerio no tenía nada de profanatorio, tal vez sí de extravagante o excéntrico. De igual opinión era Félix del Valle, que subrayaba que en el peor de los casos era una irreverencia, vista desde una perspectiva tradicional, pero nunca profanación, por ser un arte, un acto místico, como puede ser una procesión entrando al camposanto (Revista de Actualidades, 10-XI-1917, pp. 5-7). En ese punto todos ellos coincidieron con la bailarina, quién además subrayó que ella honraba a los muertos y no había irrespeto en su actitud (El Tiempo, miércoles 7-XI-1917, pp. 1-2; La Prensa, martes 6-XI-1917, edición de la mañana, p. 3.).

De hecho, la autoridad eclesiástica, aunque al inicio -véase la acción del provisor del arzobispado- se interesó en el asunto, luego desistió de presentar denuncia, y sólo la Beneficencia fue la parte interesada, aunque luego retiró la denuncia, e incluso su presidente le aseguró a Rouskaya en reunión posterior que el asunto no iría más allá, producida su libertad (La Prensa, 10-XI-1917, edición de la mañana, p. 3 y jueves 15-XI-1917, edición de la mañana, p. 6). ${ }^{4}$

${ }^{4}$ W. Stein, Mariátegui..., pp. 89. 
En este contexto narrado, empero, todavía no está muy claro para algunos el porqué de la posición del arzobispado de Lima en esta coyuntura. Se tiene una idea meridianamente clara que por un lado la actitud exaltada, denunciadora de la profanación cometida, lo tuvieron ciertos sectores sociales tildados de tradicionalistas y conservadores. El estudioso José Carlos Mariátegui asevera en este punto que "los estamentos más conservadores de Lima dramatizaron más el asunto y amenazaron con retirar a sus muertos del lugar si la sanción no era extrema". ${ }^{5}$ Mientras el investigador William W. Stein aseguraba que por un lado la actitud del diario católico La Unión fue radical, exigiendo castigo para los profanadores, pero fue muy ponderada, distinta, la actitud de las autoridades eclesiásticas -representado por el Vicario Capitular del arzobispado-: "prudentemente, no se comprometió a la Iglesia a que se pronunciara sobre el asunto". Argumentó que debido a que ello la Beneficencia de Lima tuvo que desistir de su actitud incriminatoria. ${ }^{6}$

Efectivamente, la actitud de La Unión fue radical. Era un diario dirigido por Vitaliano Berroa, que antes de 1912 se había impreso por espacio de dos años y que, según acuerdo de la Asamblea Episcopal de aquel año, recibió ayudas económicas personales de los obispos deseosos de su reapertura bajo la exigencia de defender la posición católica, aunque de no entrometerse en política partidaria alguna. Era un diario donde Berroa denunciaba el poco interés en la fe de los jóvenes y las nuevas generaciones, la descomposición social, y abogaba por una cultura católica para luchar contra la secularización creciente. ${ }^{7}$ En la coyuntura del escándalo producido llamó "infame profanación" y "actos inmorales y depravados" a lo realizado y le dedicó varios números al asunto. Aprovechó además del discurso de Mariano H. Cornejo en el parlamento para censurarlo y cuestionar que los bailes de Norka Rouskaya fueran artísticos, incluso en los teatros de Lima, pues son "tiempos de lenidad y de poca escrupulosidad ética" los que vivía la sociedad (La Unión, Lima, miércoles 7-XI-2017, p. 20 y viernes 9-XI-1917, p. 1).

Queda claro entonces la acción de los sectores sociales católicos en la coyuntura. Lo que hay que entender es el porqué de la actitud del vicario capitular, monseñor Manuel Segundo Ballón, aparentemente desmarcándose de los otros.

En este punto hay que recordar varios hechos. A inicios de 1915 había estallado un escándalo en la Escuela Normal de Varones, cuando su director

\footnotetext{
5 "El baile de Norka Rouskaya", art. cit.

${ }^{6}$ W. SteIn, Mariátegui..., pp. 76 y 89.

7 Ver Josep I. Saranyana y F. Armas Asin, La Iglesia contemporánea en el Perú (1900-1934). Asambleas Eclesiásticas y Concilios Provinciales. Lima: Instituto Riva-Agüero - Pontificia Universidad Católica del Perú, 2010, p. 116-118.
} 
J. A. Mac Knight, norteamericano y protestante, fue retirado de su puesto, según se dijo por presiones eclesiásticas, aunque también el alumnado -mayormente liberal- había ridiculizado la asignatura de religión que este había introducido (Basadre 1983, XI, p. 40). ${ }^{8}$ Luego en noviembre de 1915 se aprobó la reforma constitucional que estableció la tolerancia religiosa en el Perú, en medio de grandes tumultos, con la oposición del presidente José Pardo, pero con la mayoría de las cámaras parlamentarias y unos medios de comunicación limeños favorables a la medida (unos de los impulsores de la reforma había sido el senador Mariano H. Cornejo). La oposición de la Iglesia Católica había sido pública y se manifestó en una carta pastoral del arzobispo limeño Manuel García Naranjo y de otros obispos del Perú, en la movilización de la Unión Católica de señoras, los colegios de Lima, y de los diputados y senadores católicos. ${ }^{9}$

Pero el 10 de setiembre de 1917, apenas unas pocas semanas antes del escándalo del cementerio moría el arzobispo García Naranjo, haciéndose cargo del gobierno arquidiocesano -por encargo del Cabildo Eclesiástico- el obispo auxiliar de Lima, Manuel Segundo Ballón, como Vicario Capitular. La muerte del arzobispo había traído también una confrontación con sectores liberales limeños, pues dado que el cuerpo del prelado fue expuesto en solemnes exequias cinco días en la Catedral de Lima, para que todas las corporaciones y personas pudieran participar, el abogado Manuel Químper -el mismo que luego defendió a Rouskaya- protestó, por sobre exponerse dicho cuerpo tantos días, aduciendo motivos de salud pública. Respondió a esta protesta como abogado del arzobispado Germán Arenas, quien unas semanas después, como ministro de Gobierno, ordenaría prisión preventiva a los inculpados de la profanación ( $E l$ Amigo del Clero XXVI, 15-XI-1917, núm. 911, p. 558).

En esta sucesión de acontecimientos llega a Lima el nuevo Nuncio, Lorenzo Lauri, quien presenta sus credenciales al gobierno, siendo la ceremonia muy publicitada. Mientras el 27 de octubre el Congreso de la República, según ley, nomina a monseñor Emilio Lissón y Chávez como nuevo arzobispo de Lima, para ser presentado al Romano Pontífice (El Amigo del Clero XXVI, 15-XI-1917, núm. 911, pp. 549 y 554).

Claramente la situación era delicada para la Iglesia limeña, por los duros enfrentamientos públicos anteriores y el paréntesis en el gobierno eclesiástico que se vivía. Cuando estalla el escándalo del Cementerio la actitud del Vicario Capitular es muy prudente, frente a una opinión pública al inicio exaltada y un ministro de Gobierno que decide ordenar el apresamiento de los artífices del acontecimiento. Si bien monseñor Manuel Segundo Ballón envió un oficio a

\footnotetext{
8 Jorge Basadre, (1983), Historia de la República del Perú. Once volúmenes. Lima: editorial universitaria.

${ }_{9}$ Ver F. Armas Asin, Liberales, protestantes y masones. Modernidad y tolerancia religiosa. Perú, siglo XIX. Cuzco y Lima: Centro Bartolomé de las Casas y Pontificia Universidad Católica, 1998, pp. 185-204.
} 
la Beneficencia, solidarizándose con la institución por la profanación cometida -en un momento que ella pretendía seguir con la denuncia a los acusados- y ordenar que pase al Provisor del arzobispado el pedido del Promotor Fiscal para el esclarecimiento de lo ocurrido (La Unión, Lima, jueves 8-XI-1917, p. 1). Sin embargo, con el paso de los días, la liberación de los inculpados, la creciente beligerancia producida y la actitud de medios como La Prensa, La Crónica, El Tiempo y diversas revistas, finalmente opta por no participar de la denuncia de la Beneficencia pues legalmente no le correspondía, dado que el acto había ocurrido en el recinto de una institución pública.

Lo cual no quiere decir que como autoridad moral y espiritual limeña no tuviera una opinión al respecto. Según expresó un diario, Norka Rouskaya, una vez libre visitó al vicario capitular para expresarle su respeto a los muertos, las inexactitudes que se decía sobre lo que hubiese cometido "alguna incorrección que pudiese significar alguna irreverencia y menos una profanación", para que se convenciera de la "pureza de su aventura artística" (El Tiempo, viernes 9-XI1917, p. 2).

Ello nos permite entender por qué una semana después de lo ocurrido, cuando Norka Rouskaya ya se había marchado de Lima, prosiguiendo con sus actividades profesionales y los periódicos limeños habían pasado a otras noticias cotidianas como centro de atención, el vicario capitular, dirige una carta a la feligresía, de fecha 13 de noviembre, indicando:

Profundo pesar Nos ha causado la sacrílega profanación del Cementerio Católico de esta ciudad, perpetrado... hecho lamentable que ha conmocionado hondamente a todos las clases sociales y consternación que ansían una pronta reparación.

(...) no Nos preparamos para calificar la naturaleza especial ni la magnitud de aquel hecho, ni menos la culpabilidad de los autores. Por el contrario, queremos creer que al perpetrarlo han procedido sin pensarlo debidamente, y por eso les perdonamos y pedimos a Dios que los perdone, si acaso alguno hubiesen contraído.

Consideramos, pues tan solo el hecho notorio de la profanación independientemente de sus actores y las razones que en pro y en contra se aleguen" (El Amigo del Clero, XXVII. 1-XII-1917, núm. 912, p. 593).

Deja pues claro que no le interesa entrar al debate de las autorías del hecho, pero sí subrayar que lo efectuado fue una profanación. Sigue en el documento una larga y fina descripción de la posición doctrinal de la Iglesia sobre el cuerpo desprendido del alma, que es sagrado, que no se puede profanar en espera del juicio final, para que se reúna con el alma. Se señala en esa lógica que el cementerio es el sitio de reposo de esos cuerpos, donde es querido y cuidado por sus familiares. Por ello termina la carta anunciando una misa pontificada De Requiem, a las 9:30 am del domingo próximo, 18 de noviembre. Será una misa de sufragio por las almas de los cuerpos que descansan en el Cementerio,

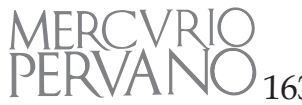


siendo el padre descalzo Francisco Aramburú quien tendrá el discurso fúnebre, invitándose a participar a las corporaciones e institutos religiosos, a la Unión Católica, Tercera Orden Franciscana, cofradías, asociaciones y fieles en general (El Amigo del Clero, XXVII. 1-XII-1917, núm. 912, pp. 593-595).

El texto también fue publicado por el diario La Unión (La Unión, jueves 15-XI-1917, p. 1)..$^{10}$ Ante el anuncio los párrocos de la capital deciden, mediante aviso, convocar igualmente a una plegaria en común, "en sufragio de los seres queridos cuyos restos mortales reposan", acto a llevarse a cabo en el cementerio ese mismo día a las 4 de la tarde, como reparación por lo ocurrido (La Unión, jueves 15-XI-1917, p. 1 y 18-XI-1917, Hoja Dominical, p. 259). No se sabe si fue una iniciativa de un grupo de párrocos, un acto independiente, o por el contrario en coordinación con la autoridad vicarial.

En todo caso lo que queda meridianamente claro es que ni la actitud del prelado fue de desentendimiento ni su posición fue diametralmente opuesta a los sectores sociales católicos que ya se habían expresado. No es como cree Stein que "a pesar de la declaración del Vicario Capitular", La Unión, continuó considerando "el incidente como una profanación". ${ }^{11}$ Es cierto que el diario siguió llamando a los autores del incidente como "jóvenes casquivanos" y al acto como profanación, argumentando que había generado repulsión en la sociedad limeña. Pero también es cierto que el vicario consideró que aquello había sido realmente una profanación, aunque sin señalar nombres.

Para la Iglesia había sido una humillación a los muertos, a la misma feligresía, al cuerpo de Cristo. En la misa de la Catedral de aquél domingo 18 de noviembre se puso en la bóveda central cortinas de luto, siendo recubierto el púlpito con paños negros y los altares con adornos de luto. Asistieron aparte de las corporaciones eclesiásticas, el público en general, periodistas cercanos a la Iglesia, representantes del gobierno, y en la oración fúnebre el franciscano Francisco Aramburú recordó que incluso en las naciones de "paganos y gentiles" se respetaba a los muertos y no se permitía su profanación "bajo pretexto alguno". El responso lo realizó monseñor Lorenzo Lauri, nuncio apostólico, rodeado de los miembros del cabildo eclesiástico (La Unión, lunes 19-XI-1917, p. 1).

Por la tarde, en el cementerio, la multitud católica, en forma ordenada empezó su ingreso al recinto: primero los boy scouts de la parroquia de Santa Ana, luego las asociaciones piadosas, luego los grupos de obreros católicos, luego la Unión Católica de caballeros y finalmente las corporaciones religiosas, entonando el salmo De profundis, haciéndose responsos en varias estaciones, incluyendo la gradería frente al mausoleo de Ramón Castilla. Allí el padre Aramburú de nuevo agradeció la actividad y dijo que el "católico pueblo de

\footnotetext{
${ }^{10}$ SteIn publicó parte del mismo, aunque con varios errores de transcripción, en Mariátegui..., p. 89.

11 W. Stein, Mariátegui..., p. 90.
} 
Lima... sabe mantener enhiesta la bandera de Cristo, a despecho de lo que hace la impiedad por descatolizarlo" (La Unión, Lunes 19-XI-1917, p. 1).

\section{III}

Una persona que firmó como J.O.Z, escribió una carta en el diario La Prensa, en los días del escándalo, argumentando que la autoridad religiosa había declarado que no había existido ni inmoralidad ni hecho de sangre, causales de profanación, y por tanto no procedía una reconciliación canónica como algunos laicos católicos habían pedido: "La autoridad eclesiástica pues en este caso, ha tenido... más tranquilidad de criterio que los periodistas, y hasta que algunos representantes... en el seno del Congreso" (La Prensa, martes 6-XI-1917, edición de la mañana, p. 3).

Ha existido en los estudios sobre el escándalo del cementerio de 1917 una cierta posición de presentar a la autoridad eclesiástica por un lado supuestamente planteando que no hubo profanación y por otro lado una posición de ciertos sectores de opinión clamando en ese sentido. Hemos querido aclarar el punto. La autoridad eclesiástica sí consideró que hubo profanación, aunque su mirada fue ciertamente muy serena, no arrastrándose por el torbellino del escándalo pasajero y mediático. Lo acontecido en los últimos meses y semanas, y la propia situación interna que vivía el cuerpo eclesiástico, permitieron sortear de forma satisfactoria el hecho y sacar más bien una lección pastoral para la feligresía católica, en una mirada trascendente del significado de un recinto sagrado y del descanso de los cuerpos. 